\title{
La Pintura Social en México
}

Por más que la América Latina se encuentra hoy, como nunca, ante la puja de sistemas políticos que encubren su ofensiva bajo aspectos tn gañosos, el Continente Americano comienza a sacudirse de la disposición estructural receptiva que lo aquejaba. Durante siglos adaptó sistemas y formas que nada tienen que ver con su psicología y con e! vasto escenario de su propio espacio-tiempo estético. Estos sistemas lograron infiltrarse en algunos sectores, los menos consistentes, y crearon aspecios de dominio colonial en muchos lugares, sobre todo aquellos donde más abandonada se encontraba la levadura indígena y más olvidara la tradición de la cultura autóctona.

Pero gracias a la fuerza vital que se desprende, tanto de la raza aborigen como de los rezagos de las culturas nativas que parecían muertas, ha llegado la hora del resurgimiento. Indoamérica parece hoy convertirse de receptiva en irradiante.

Después de largo evolucionar por rutas artificiales, se despierta en los pueblos de América ese deseo oscuro que analiza Spencer en la humanidad, por retroceder lo andado. $Y$ ya que no se puede volver a las primitivas formas sociales o políticas, el esfuerzo se encamina hacia la gran nacionalidad que comienza a vislumbrarse en el arte indoamericano.

El arte Indoamericano nace en México con la revolución de 1910. La Revolución Mexicana constituye el "salto biológico" que estudia Plejanov, y el Arte Indoamericano es la expresión de ese proceso constructivo que tuvo su sacudimiento realizador cuando las masas populares y campesinas de México se movieron reclamando "Libertad y tierras". Con los mismos caracteres imprecisos, instintivos, con que apareció la Revolución, se inició el primer ejemplo de arte decididamente revolucionario que contempla el mundo contemporáneo. Ya Proudhon había sentado las bases filosóficas y sociales de este arte. Para la humanidad revolucionaria, que comienza su propia creación por la conciencia de sus derechos, el artista "es uno de los principales agentes de esta creación". Y el derecho de la revolución se funda en que las obras de arte "que en el pa- 
sado eran auxiliares de la libertad y la moral, se han convertido en instrumentos de tiranía y corrupción, signo de explotación y miseria".

La expresión revolucionaria mexicana desde la cuna se vió desligada de teorías estéticas artificiales y extranjeras. Los artistas mexicanos, para expresar el arte revolucionario, no tuvieron que recurrir al ecléctico arsenal de los estilos internacionales. No había más que asomarse al escenario de México, agitado por fuerzas vivas y palpitantes, par a "encontrar" las ideas y anhelos que despuntaban en el revielto estado social. Allí estaba el material de primera mano que necesitaban.

Para la figuración de este escenario el artista mexicano está dotado de cualidades psicológicas de penetración y cualidades intuitivas, cua. lidades biológicas heredadas, favorablemente desarrolladas por especiales circunstancias sociales. Inspirándose en la representación objetiva, guiados por el aspecto formal y la novedad de los acontecimientos que revolucionaban el medio, rechazando lo ficticio y decorativo, se hicieron realistas. $Y$ este exaltado realismo lo vemos aparecer con carácter "verista".

La mitología en México había cumplido su misión. Sus comandos espirituales fueron suplantados con conceptos sociales. Los sistemas que regían al país, resultado de una imitación a priori de sistemas extranjeros, cedieron ante la expresión que imponían el medio y los acontecimientos. La conciencia propiamente dicha, surgió con caracteres propios después de un siglo de gestación. Mientras los caudillos y generales daban sus últimas batallas brotó la expresión estética de un nacionalismo continental cuyas fronteras podemos señalarlas por el norte en el Río Bravo y por el sur en el Estrecho de Magallanes.

En toda América se inició un nuevo período histórico, un nuevo ciclo que el argentino Ricardo Rojas llama "eurindia", coalición de dos elementos: europeo e indígena, y el mexicano Vasconcelos denominó, "indología"; "una tradición cultural española-indígena, europea y americana, un continente deshabitado y rico y una raza mixta, producto de todas las razas conocidas, la raza mixta total, el primer caso de raza positivamente universal".

La Indología, según Vasconcelos, no ampara ninguna intención de predominio favorable a la tradición autóctona de América o a la raza indígena del continente. "El factor particular que dicha raza representa, dice, lo juzgo únicamente en ia proporción humana y fraternal a que tiene derecho junto con las demás razas que han de concurrir a la nueva era del mundo". 
El concepto que encierra la palabra "Indoamericano", coincide con esta exclusión de predominio racial, pero se limita a hacer continental la relación espiritual y materialista. Se sujeta a la realidad sin llevarnos a los campos universales de la Indología o a los limitados campos de "Eurindia". Se encierra en el espíritu de América. En América, nos dice Haya de la Torre (1), se oponen diversos períodos de la evolución histórica que en otros continentes se suceden, agregando: "El Hispanoamericanismo corresponde a la época colonial, dominio español. Latinoamericanismo a la época republicana, predominio espiritual de los enciclopedistas y la civilización latina. Panamericanismo, expresión económico-política, dominio imperialista. Por último "Indoamericanismo", vocablo integral legitimado por la unidad o la tendencia hacia la unidad espiritual del continente".

El Indoamericanismo se basa en la comunidad étnica y cultural de las naciones del continente americano, reconociendo un solo tipo espiritual. La cordillera de los Andes es el punto de partida del ethos americano. Aunque separadas, las naciones de América han vivido bajo la misma latitud espiritual, sacudidás por idénticos cataclismos geográficos y las mismas calamidades sociales. No hay necesidad de predominio de sangre india, española o italiana para sentir y pensar como indoamericano.

"Por el intercambio de las ideas, por la creación artística, por los grandes hechos de los hombres, surgirá entre los pueblos americanos una cultura valiosa y original"' dice Uriel García (2). Ya hay prueba de la nueva cultura. Se revela en la expresión artística, en el Arte Indoamericano.

El Indoamericanismo rompe, al parecer, con la evolución histórica del contenido. Dá forma al Arte en América. El período republicano es como un vacío, desde la "independencia" hasta la revolución iniciada en México. Nuestro siglo XIX en algo se asemeja a la dislocación social que en el medievo separa el Imperio Romano del Renacimiento. Transcurre entre el desenfreno de generales "montoneros", atisvos del romanticismo y media ciencia de las oligarquías universitarias. Se desconoce el papel que el arte desempeña. No hay otra mística que la de los caudillos; en filosofía prima el pesimismo alemán, en literatura el preciosismo decadente de los franceses. En escultura los santos de yeso de Hamburgo, en pintura los cromos de todas partes. "América, como

(1) "¿A dónde va Indoamérica?" Edit. Ercilla.-Santiago de Chile.

(2) "El Nuevo Indio". Uriel García. Editorial Rozas.-Cuzco. 
dice Luis Alberto Sánchez, practicó el decorativismo, la fórmula se irguió señera: batuta de una sinfonía tropical".

Pero ese enorme espacio de un siglo cumplió su misión histórica de eliminación y gestación. El proceso constructivo del determinismo histórico no admite revoluciones hechas por individuos. El proceso formativo del arte tampoco. Cuando los artistas revolucionarios de México lanzaron su manifiesto secundando la revolución de las masas, obedecían a profundos y milenarias mandatos. Las escuelas y los sistemas no nacen arbitrariamente de manifiestos o lucubraciones imaginativas. Obedecen a profundas realizaciones. Si florecen $-\mathrm{y}$ el arte americano dá trazas de florecer- es porque nacen como todos los fenómenos sociales, de la trascendencia de los hechos y con la misión de expresarlos. Si el arte mexicano ha llegado a extenderse en Norte y Sudamérica, no es sólo porque en la obra han contribuído artistas de mérito. El arte de Rivera, de Orozco, Castellanos, Mérida y otros pintores indoamericanos, contiene además del trabajo y genio de los cultivadores, el legado milenario de las culturas autóctonas.

Un estudio histórico nos demostrará que el Arte Indoamericano depende tanto de las mitologías autóctonas como de los dogmas cristianos, aunque la función intermediaria entre la mitología y el dogma sea diferente. La mitología autóctona, contrariamente al dogma cristiano, no conoció doctrinas verdaderamente trascendentales; sus dioses estaban constituídos por un mundo humano, accesible sólo a la claridad plástica. El cristianismo, por el contrario, está lleno de dogmas, como el de la Trinidad, incompatibles con la fantasían humana. Su sesencia no proviene de los esfuerzos prodigiosos ni de la imagen prominente del hombre sino de la gloria de Dios.

El uno aporta su concepto de concreto y perceptible. Su contenido, por fantástico que sea, se relaciona siempre con los sentidos, corresponde a la fantasía artística. La esencia del arte cristiano, por el contrario, no está en relación con los sentidos ni sometida a la percepción. Está constituída por ideas que no podemos concebir ni expresar directamente. El arte precolombino existe a causa de la mitología, el arte cristiano a pesar de su dogmatismo. El artista precolombino dá una realidad objetiva al mito, ligándolo a su origen natural y humano. El artista católico, desde la colonia, se doblega o se rinde ante el sensualismo pagano del indio. Se apoya en sus bases materiales, como otrora en la mitología griega, para amplificar y robustecer su teología. El artista moderno de México es materialista. Se basa en los símbolos de la mitología precolombina, ya que no puede haber arte nacional si carece de una base mitológica o 
social propla donde apoyarse. Quiere decir una mitología proveniente del mismo suelo, del mismo fondo cultural, del mismo orden económico. También se basa en la nueva mística social revolucionaria. El mito surge en América como un producto de la fantasía del pueblo. No existía en el Perú o en México una casta sacerdolal y un arte hierático como en Egipto, que creaba las mitologías. Estas se produjeron, como los conceptos del cristianismo, uniendo las dos tendencias: la del desarrollo popular y natural y la emanada de la organización de la Iglesia.

Hasta la aparición del arte revolucionario mexicano, América cultiva un arte prestado a las artes europeas. Este arte fué desechado por los artistas mexicanos que, siguiendo el materialismo histórico, deducían los hechos de las concepciones políticas, jurídicas, etc., tal como se desprendía de las realidades económicas fundamentales. Es verdad que así se ponían en desventajosa posición al lado de las filosofías idealistas, que hacen resaltar las características específicas de los dominios del espíritu.y de la cultura. Pero los artistas mexicanos, a pesar de su materialismo, no descuidaron el lado sustancial que quedaba por expresar en las mitologías nacionales. Cada mitología domina, interpreta las fuerzas de la naturaleza por la imaginación, pero su presencia no es necesaria una vez que el dominio científico se ha hecho efectivo. Por eso los artistas mexicanos, de una manera casi instintiva, descuidaron los aspectos naturales de esa mitología; no trataron, como los artistas reaccionarios, de refugiarse en lo metafísico y simbólico. La siguieron en su transformación y en su figuración histórica. Sin ayudarse de artificios, penetraron en la naturaleza de los hechos, dando al arte, una orientación al mismo tiempo social, ideológica y mtaerialista.

Como símbolo y como mística tomaron al indio. El contenido es la acerba lucha emprendida para conquistar su dignidad de ser humano. Tomaron al indio, no como personaje decorativo, ornamentando un paisaje con los vivos colores del poncho, ni cantando con la guitarra, en exóticas fiestas cinematográficas; al indio en su verdadera representación. El indio ancestral, el indio que tomó posesión de su tierra mexicana con la clarinada de la revolución; que fecundó la tierra con su cuerpo sufrido y sangró su dolor sobre los campos resecos, matando su hambre en la escuálida nopalera, apagando su sed de ensueños en el líquido viscoso de los magueyes.

Desde los primeros murales de técnica renacentista y de eclécticos reflejos europeos: sintetismo gauguinesco, "valore plastici", post expresionismo, puerilismo roussoniano, se nota la subsistencia de las divinidades del Anahuac, resucitadas en cuerpo y alma: Tlaloc, Quetzacoatl, 
Huizilopochtli, la diosa de la lujuria, los Señores de la Noche, reaparecen en las revoluciones sangrientas de la República. Bajo diferentes aspectos podemos ver en los cuadros el ascetismo de Guadalupe Victoria, la frialdad de Juárez, la sonrisa amenazante de Pancho Villa, el gesto agresivo de los "cristeros" llevando en andas a santos empenachados, como otrora a los dioses turbulentos, símbolos de coraje, fuerza y audacia.

El mismo fenómeno de supervivencia podemos observar en Suramérica al surgir el Ârte Indoamericano, aunque con menos homogeneidad y fuerza plástica. Es india y americana el alma que reza padrenuestros en latinajos que tienen cadencias quichuas. El patrón milagroso de Cusco, "Taitacha Temblores", un Cristo ético que el día de Corpus pasea su dolor por las calles de la ciudad imperial, es un Cristo mestizo. Pálido de agonía llegó de España hace tres siglos. Las lluvias, el sol, el humo del incienso han renegrido su cuerpo, y ahora, pese a la pollera de encaje que pende de su cintura, a los colores republicanos que flamean al viento, es un ídolo indígena que abre los brazos, promisorios de esperanzas, sobre un pueblo que hace siglos espera ser reintegrado a la vida libre.

Áctualmente el Arte Indoamericano se muestra en pleno desenvolvimiento, revestido de importancia y guardando plena armonía entre composición, forma y contenido. El tema puede variar según los países, pero la expresión artística es la misma. Y si en el arte indoamericano encontramos expresados ideales universalmente humanos, es por la amplitud y riqueza del "contenido, sin dejar por eso de transparentar en nuevas formas, las experiencias psicológicas, sociales y económicas de los pueblos de América.

Entre los nuevos cultivadores de la pintura mexicana hay algunos que no quieren saber del Arte con filosofía social. Prefieren el surrealismo freudiano. Siguen a Chirico en su geometría de claros de luna y espacios desiertos y a Dali en el intento de explorar la mente subconciente, con técnica de miniaturistas.

Sin desprenderse del todo de la expresión idealista y guerrera de la revolución, siguen el lirismo surrealista pintando en medio de una arquitectura freudiana, escenas de batallas y fusilamientos iluminados con reflejos boreales, como debe ser la luz del más allá. Soldaderas con andar de brujas, despojando a los muertos después del combate. Visión goyesca de ajusticiados al pie de muros salpicados de sangre. Ventanas abiertas al infinito. Nácar de caracoles, misterios de ataúdes... Las manos son características inconfundibles de la pintura mexicana. Expresan 
potencia y fuerza en Diego de Rivera, angustia en Orozco, y en los cuadros de algunos sucesores gestos elegantes saturados de nostalgia. Traduceil un período que no maldice, ni pide, ni ofrece. Esperan en alto.

El realismo "verista" de los mexicanos en el retrato, confirma el calificativo que merecen de "grandes pintores". El pintor de retratos, cuando no se somete a la lisonja, cuando dispone de la facultad de penetración psicológica y libra al modelo con todas las trazas de su espíritu, emprende, a la vez, una labor social e histórica.

En el género de retratos, desde el siglo XIX, los pintores de México tienen la facultad de hacer traslucir la materia substancial, pletórica y sensual del indio. Hay fantasía caprichosa. Candor (puerilismo). La mismo simplicidad con que el aduanero Rosseau cautivó a Europa. $Y$ eso que Rosseau la trasplantó desde México a los artificiales jardines de París, como flor de invernadero.

DIEGO RIVERA, es el artista indispensable, ineludible, cuando se habla de pintura, no sólo mexicana sino universal. Se le considera como uno de los más grandes pintores modernos. Sus panegiristas forman legión. Este artista posee un talento excepcional, un gran espíritu de captación y una gran habilida dtécnica. Su obra pictórica culmina en los murales de la capilla de Chapingo. Su rango de genio también termina ahí. Su composición tiene un sentido neo-clásico, occidental. Pero a pesar de la supeditación del tema al valor plástico, esos murales encierran la génesis del indoamericanismo que han de surgir más tarde. En los muros, planeados con firmeza, sin vacilaciones, están todos los elementos que han de utilizar más tarde los pintores de Indoamérica; después de ésto, el resto de la obra de Rivera no importa. Después vinieron los críticos con sus excesos de literatura, vino Siqueiros, vino el surrealismo, se apagó el fuego revolucionario que exaltaba las conciencias y se dispersaron sus discípulos en busca de otras ideologías. Pero el movimiento estaba iniciado y la pintura mexicana se encontraba bien plantada. Con base sólida.

FELIPE COSSIO DEL POMAR. 